\title{
Frugivorous Bird Guild Seasonal Patterns in Semiarid Chaco Forests are Linked to Habitat Seasonality but Reveal Phylogenetic Signature
}

\author{
Diana E. Marco ${ }^{1 *}$, Sergio A. Páez ${ }^{2}$ and Gabriel Boaglio ${ }^{3}$ \\ ${ }^{1}$ Laboratorio de Ecología Matemática, Area de Producción Orgánica, Facultad de Ciencias \\ Agropecuarias, Universidad Nacional de Córdoba, and CONICET, Ciudad Universitaria, CC 509, \\ 5000 Córdoba, Argentina. \\ ${ }^{2}$ Instituto Universitario Aeronáutico, 5000 Córdoba, Argentina. \\ ${ }^{3}$ Facultad de Ciencias Naturales, Universidad Nacional de Córdoba, 5000 Córdoba, Argentina.
}

\section{Authors' contributions}

This work was carried out in collaboration between all authors. Authors DEM and SAP designed the study. Author DEM performed the statistical analysis and wrote the manuscript. Authors DEM, SAP and $G B$ collected field data, author GB performed bird surveys. All authors read and approved the final manuscript.

Article Information

DOI: 10.9734/JSRR/2015/14076 Editor(s):

(1) Luigi Rodino, Professor of Mathematical Analysis, Dipartimento di Matematica, Università di Torino, Italy.

Reviewers:

(1) Lucas Ricardo Petigrosso, National University of Mar del Plata, Argentina. (2) Anonymous, Institute Cavanilles of Biodiversity and Evolutionary Biology, Spain. (3) Anonymous, Universidad Nacional de Tucumán, Argentina. Complete Peer review History: http://www.sciencedomain.org/review-history.php?iid=747\&id=22\&aid=7186

Original Research Article
Received $17^{\text {th }}$ September 2014 Accepted $17^{\text {th }}$ November 2014 Published $15^{\text {th }}$ December 2014

\section{ABSTRACT}

Aims: This work aims to explain seasonal changes in frugivorous bird species richness, abundance and diversity, addressing climatic and habitat variables (rainfall, Photosynthetically Active Radiation as PPDF) and species' trait factors (diet), while considering the effect of phylogenetic constraints.

Place and Duration of Study: Forest Reserve of Chancaní, Córdoba Province, Argentina ( $31^{\circ} 2^{\prime} \mathrm{S}$ and $65^{\circ} 25^{\prime} \mathrm{W}$ ), during 1995-1996.

Methodology: In the study area two randomly located sampling points separated each other by two $\mathrm{km}$ were established. Phenological records for seven forest plant species producing fruits were taken monthly, along with habitat and climatic variables (PPDF, rainfall). Bird sampling was done 
monthly. Fourteen transects, each of $50 \mathrm{~m}$ long were permanently marked from randomly located points in N-S direction. While slowly walking along each transect, all bird sightings as well as hearings both to right and left sides were recorded. The bird species and the vegetation stratum where the sighting occurred were also recorded.

Statistical Analysis: For all the bird species and for frugivorous species, bird species richness (S), species abundance as sightings, diversity (Shannon Index $H^{\prime}$ ) and evenness $\left(\mathrm{H}^{\prime} / \mathrm{InS}\right)$ were calculated for each sampling date. Friedman test was used to test differences in species richness and sightings among dates. For frugivorous bird data analysis, two approaches were used, one with the species values taken as independent data points, and the other removing phylogenetic effects by means of the analysis of independent contrasts. Categorical Principal Component Analysis (CATPCA) was used to explore the relationships among species dates of sighting initiation, duration of the sighting period and abundances at peak dates, using species values and independent contrasts. CATPCA (with species values) was also used to explore the relationships among frugivorous bird species richness, abundance and diversity, and climatic (rainfall) and habitat (PPDF and fruit abundance) variables.

Results: A total of 67 species were recorded during the sampling period. Richness rose in spring, peaked during summer and then declined smoothly to winter. In contrast, abundance maintained fluctuating values during the sampling period, with a small peak in autumn. There were no significant differences in vegetation strata occupancy by different species of birds, although some groups showed a degree of preference.

Considering frugivorous birds, a total of 29 frugivorous species were recorded during the sampling period. The temporal trend of species richness and diversity was similar to the pattern showed by all the species, although abundance showed a bimodal trend. CATPCA using species values and independent contrasts showed common overall results for the variables initiation and maximum of frugivorous species abundance, that were inversely or not correlated with duration of sightings, maximum abundance and total abundance along the sampling period. However, the behaviour of the variable Diet changed when independent contrasts were used. From a closer relationship with sighting initiation and peak and a greater importance with species values data, Diet showed a more distant relationship with these sightings variables and a negligible value when independent contrasts were used. Besides, using independent contrasts many species were differently related with the variables and the dispersion of the species was greater in the ordination space.

Regarding climatic and habitat variables, rainfall and PPDF showed an overall similar seasonal pattern, although PPFD began rising earlier during the dry season. Rainfall and PPDF were temporally correlated. Fruits began appearing in spring, peaked during this season, and then decreased sharply to disappear during winter. Fruit abundance was highly correlated with PPFD but not with rainfall. CATPCA of climatic, habitat, and frugivorous bird variables (richness, abundance and diversity) separated spring, summer and autumn sampling dates from the last autumn date and winter dates. PPDF and fruit abundance explained most of the variance in bird richness and diversity but not in abundance. Rainfall did not explain the behaviour of any bird variable.

Conclusion: We conclude that habitat characteristics, mainly PPFD and fruit abundance, are shaping the seasonal species composition (richness and diversity), although not abundance, of frugivorous bird assemblages in semiarid Chaco forests. The importance of the frugivorous diet diversification, as a species' trait factor that could be contributing to shape the seasonal arrangement of frugivorous birds, was secondary and mainly related to the timing of appearance in the favourable season. However, even this modest contribution of diet diminished when the phylogeny were taken into account, showing a strong phylogenetic signal.

Keywords: Forest bird seasonality; frugivorous birds; climatic and habitat variables; fruit phenology.

\section{INTRODUCTION}

Seasonal changes observed in bird species composition, population abundance and guild structure in semiarid forests have been attributed to the strong climatic seasonality of these habitats [1,2]. Seasonal fluctuations in rainfall and temperature cause changes in vegetation phenology that in turn affect habitat structure and resource availability for birds including fruits [1]. These climatic and habitat characteristics are considered major factors in structuring bird assemblages [2-6]. Lately, complementary explanations focusing on the organismal and 
ecological traits influencing fitness (hereafter termed species' traits) as factors that can predict species seasonal responses have been proposed. For example, results from Diamond et al. [7] demonstrate that species' traits (diet breath, dispersal ability and others) can be important predictors of responses to climate change in timing of appearance of UK butterflies. In bird community studies the species' trait mostly used is the type of diet, to group species into trophic guilds $[8,9]$. Underlying these factors, there may be phylogenetic constraints shaping seasonal changes in bird assemblages. It is known that related species share traits through common descent [10]. In birds, for example, beak morphology and type of digestive system, as shared evolved traits, conditioned the trophic behaviour of related species [11,12]. In another example, seasonal changes in migrant birds showed a strong phylogenetic signature in the European avifauna [13].

In neotropical forests climatic and habitat characteristics have been taken into account to explain the seasonal patterns of birds (for example [14,15]). However, in our knowledge, the relevance of a potential phylogenetic signature have been not explored yet. This work aims to explain seasonal changes in frugivorous bird species richness, abundance and diversity, addressing "habitat variables" and the "species" traits" factors, while considering the effect of phylogenetic constraints, in a semiarid Chaco forest from central Argentina. Although the work was focused on the frugivorous guild due to its importance for trees and shrubs dispersion in this type of forests $[8,16]$, to present this particular guild in context a brief account of the seasonal changes of the entire bird community is also given.

\section{MATERIALS AND METHODS}

\subsection{Study Site}

The Forest Reserve of Chancaní, Córdoba Province, Argentina ( $31^{\circ} 2^{\prime} \mathrm{S}$ and $65^{\circ} 25^{\prime} \mathrm{W}$ ). was chosen as study site. The Reserve covers an area of $500 \mathrm{~km}^{2}$, from $1000 \mathrm{~m}$ elevation in a steep slope down to $300 \mathrm{~m}$. The mean annual rainfall reaches $500 \mathrm{~mm}$, of which 80 percent occurs in summer months (weather data recorded at the study site between 1982 and 1991). Precipitation mainly occurs at night or dawn hours as short, heavy showers, and skies generally remain clear during the day [17]. There is a severe dry season between April and October. Summer mean maximum and minimum temperatures are $35^{\circ} \mathrm{C}$ and $20^{\circ} \mathrm{C}$, respectively, with mean temperatures of about $27^{\circ} \mathrm{C}$. Vegetation belongs to the Occidental Chaco Forest region [18]. Tree stratum reaches $20 \mathrm{~m}$ and is dominated by Prosopis spp. and Aspidosperma quebracho-blanco Schlecht., and the shrub layer is dominated by Larrea divaricata, Mimozyganthus carinatus (Griseb.) Burk and Acacia furcatispina Burk. [19]. The area sampled in this study was located in a forest occupying the plain area of the Reserve without clear-cut since 1920 (Supplementary material, Fig. S1). In this part of the Reserve tree and shrub richness is about 20 species [20].

\subsection{Bird Data Collection}

The bird data related to diet and residence status was based in previous research [2,21-25].

Bird sampling was done monthly, from October 1995 to August 1996, beginning with two spring samplings (hereafter Spr1, Spr2), going through three summer (Sum1, Sum2, Sum3) and three autumn (Aut1, Aut2, Aut3) samplings and ending with three winter (Win1, Win2, Win3) samplings. Bird sampling was conducted by the same person to avoid personal biases, from dawn to nine in the morning (during two consecutive days, three hours each day), covering the hours of highest bird activity. Fourteen transects, each of $50 \mathrm{~m}$ long were outlined from randomly located points in N-S direction, covering an area of $16 \mathrm{~km}^{2}$ of forest. Minimal distance between transects was $500 \mathrm{~m}$, and a strip of $500 \mathrm{~m}$ was left around the study area, to avoid edge effects. Each month, the same fourteen transects were sampled. While slowly walking along each transect, all bird sightings as well as hearings both to right and left sides were recorded. As visibility in this kind of forests is greatly reduced due to the dense shrub stratum, a relatively short distance at each side of the transect (ten meters) was taken into account for visual bird detection. For each sighting, the bird species and the vegetation stratum where it occurred were recorded. Three different vegetation strata were defined as: S1, tree stratum, from 3 to $20 \mathrm{~m}$ (the maximum tree height); $\mathrm{S} 2$, shrub stratum, from 1 to $3 \mathrm{~m}$; and S3, herbaceous stratum, from 0 to 1 $\mathrm{m}$. Detectability in the tree stratum might have been higher compared to the lower strata, and also, may vary for different species.

\subsection{Plant Species}

For a detailed analysis of seasonal patterns of frugivorous birds, seven plant species were selected for the study: Condalia microphylla 
Cav., Zizyphus mistol Griseb., Celtis pallida Torrey, Maytenus spinosa (Griseb.) Lourteig \& O’Donell, Castela coccinea Griseb., Ximenia americana L. and Ligaria cuneifolia (R. et P.) Thiegh. These plant species represent the most common species of the subdominant forest layers composing the bird dispersal guild in the Dry Chaco, which is composed of 15 trees and shrubs [20]. Plant species ecological characteristics related with bird activities (life form, patterns of leaf shedding, fruit type and fruit or seed dispersal agent), were determined by direct field observations and from literature [26] (Supplementary material, Table S1). All the selected species are pollinated by wasps, bees and flies, except $L$. cuneifolia, pollinated by hummingbirds [27].

\subsection{Plant, Climatic and Habitat Data Collection}

In the sampling area, two randomly located sampling points separated each other by two km, six plants of each species were permanently marked ( $n=12$ plants per species). In order to sample the canopy uniformly eight sampling branches similar in size were permanently marked on each plant. For dioecious species, only female plants (previously determined) were marked. The number ("abundance") of immature and mature fruits in each branch was counted monthly from October 1995 to August 1996 (from Spr1 to Win3 as established in the bird sampling section). Photosynthetically Active Radiation (PAR), is an important variable to characterise plant habitats, as it is the energy source used for plants to perform photosynthesis and hence, biomass accumulation [28]. As an estimate of PAR, Photosynthetic Photon Flux Density (PPFD, $\mu \mathrm{mol} \mathrm{m} \mathrm{m}^{-2} \mathrm{~s}^{-1}$ ) was measured with a LiCor Photometer (LI-190SB quantum sensor) at soil level in ten points randomly chosen in each sampling point. PPFD measurements were taken in a single sunny day during each phenological sampling, between 11:00 and 13:00 h. Monthly rainfall was recorded near the sampling points.

\subsection{Data Analyses}

For each bird species, initiation, peak and end dates of sightings were expressed as days accumulated since the beginning of the sampling (Spr1, $1^{\text {st }}$ October 1995). Duration of sighting period was defined as the amount of days elapsed from the first sighting date (initiation) to the last one (end date). Peak was the date with the highest sighting (abundance) record and total abundance was the sightings accumulated through the entire sampling period.

For plants, initiation, peak and end dates of the fruit stage were expressed as days accumulated since the beginning of the phenological sampling (Spr1, $1^{\text {st }}$ October 1995). Duration of phenological stages was defined as the amount of days elapsed from the first fruit detection to the last one. The number of fruits used in the analyses included both immature and mature fruits, since due to the lag between sampling dates it was not possible to determine when a particular immature fruit reached the mature stage.

For the entire community of forest birds, data analysis was perfomed with the species values taken as independent data points (hereafter "species values"). For frugivorous bird data analysis, two approaches were used, one with the species values taken as independent data points, and the other removing phylogenetic effects by means of the analysis of independent contrasts [29-31] (hereafter "independent contrasts"). Independent contrasts were used in those analyses involving species traits susceptible of showing phylogenetic signals, like diet and dates of appearance. The computer package CAIC [32] in its version for PC was used. For a given continuous trait, a difference (contrast) is calculated at each phylogeny node, so that every contrast is independent from, and comparable with, the others. Then, the relationship between two continuous variables is assessed by regression forced through the origin [32]. The degrees of freedom for regression are reduced by one after applying independent contrasts. Transformation of data to decimal logarithm in the first step of analysis is required [33]. A phylogenetic tree for frugivorous birds was developed, mostly based on molecular and some taxomical trees from several authors [3447]. Development of a phylogenetic tree for all bird species was not possible because of the lack of reliable information. Branch lengths were set by default as having the same length for CAIC analysis [32].

For plants, a previous study showed that, in contrast with other phenological stages, fruit phenology is almost independent of phylogenetic constraints [16], so species value data were used instead of independent contrasts.

For each sampling date, bird species richness (S), species abundance as sightings, diversity (Shannon Index $H^{\prime}$ ), and evenness $\left(H^{\prime} / \mathrm{lnS}\right)$ were calculated. For diversity and evenness, the 
pooled data from the 14 transects were used, since there were many transects with few bird sightings. Friedman test was used to test differences in species richness and abundance among dates.

A multivariate analysis, Categorical Principal Component Analysis (CATPCA, SPSS), was used to explore the relationships among frugivorous bird species variables (timing of appearance, abundance) and diet. Diet was chosen as a relevant species 'trait since although the species included in this set consume mainly forest fruits most of them complement their diet with seeds, insects and another items like earthworms (Supplementary material, Table S2). Frugivorous diet categories were: insects + fruits (IF), omnivorous including fruits (OF), insects, earthworms and fruits (FIE). seeds and fruits (FS). CATPCA was performed using untransformed data for species values and independent contrasts. Eigenvalues and percentage of explained variance for the two firsts dimensions were retained. Cronbach's Alpha was taken as a measure of internal consistency of each dimension of the CATPCA analysis (from zero to one, higher values meaning better consistency). To show the relationships among variables and species, a biplot graph was produced, where variables are represented as vectors and species as dots. The direction of each variable vector in relation to other variable vectors and to the location of each species indicates the degree of association between them. An acute angle between them shows similarity, an obtuse angle indicates an opposite relationship, and a right angle indicates no relationship. The length of each vector is proportional to the total amount of variation accounted for by its corresponding variable.

CATPCA analysis was also used to explore the relationships among climatic (rainfall), habitat variables (PPFD, fruit abundance) and frugivorous species richness (mean number of species), abundance (as mean number of sightings), and diversity (as Shannon Index) along the sampling period.

\section{RESULTS}

\subsection{Seasonal Patterns for All Bird Species}

A total of 67 species were recorded during the sampling period. The species list is in Supplementary material (Table S2), showing their diet and residence status. Represented groups were Tinamiformes, Strigiformes, Falconiformes, Columbiformes, Caprimulgi- formes, Cuculiformes, Psittaciformes, Piciformes, Trochiliformes and Passeriformes. This last group includes almost $50 \%$ of all species. Among Passeriformes, the family with more species was Tyrannidae. Most species are characterised as residents. Some of the resident species may perform seasonal local movements during the year.

Average number of species, sightings (abundance) and diversity for all species in each sampling date are shown in Fig. 1. The number of species rose in Spr2, peaked during Sum2 and Sum3 and then declined smoothly during the rest of the sampling period (Fig. 1a). There were statistically significant differences in number of species along the sampling period (Friedman test, $x^{2}=55.75, p<.001$, df = 11). By guild, carnivorous and insectivorous species appeared and remained in the forest during summer and autumn, as well as nectarivorous species. Of 26 species that feed on seeds, 14 species stayed during summer, autumn and winter. Some other granivorous species, like Sicalis flaveola (Linnaeus, 1766), Poospiza nigrorufa (d'Orbigny \& Lafresnaye, 1837) and Leptotila verreauxi (Bonaparte, 1855) stayed only during summer. Others showed a more fluctuating presence, like Molothrus badius (Vieillot, 1819).

Considering all species, abundance (as sightings) maintained fluctuating values during the sampling period, with a small peak in Aut2 (Fig. 1b). When all dates were compared together, there were statistically significant differences in sightings (Friedman test, $X^{2}=$ 32.54, $p=.01$, df = 11). Diversity values showed by the Shannon Index showed high values during the first months of the sampling period, and then there was an abrupt fall in Aut2 (Fig. 1c), coincidentally with the sighting peak. This fall in diversity was caused by the rise in dominance of some species like Columba maculosa (Temminck 1813), Myiopsitta monachus (Boddaert 1783), Zenaida auriculata (Des Murs, 1847) and Polioptila dumicola (Vieillot, 1817). Evenness ranged from 0.92 to 0.63 , with the lower values corresponding to the sighting peak in Aut2 and the two last sampling dates.

There were no significant differences in vegetation strata occupancy by birds in each sampling date (Supplementary material, Table S3). Percentage of sightings per stratum comparing sampling dates also did not differ significantly $\left(x^{2}=0, p=.01\right.$ for each stratum). However, there were strata preferences regarding particular groups, like Falconiformes, 
Strigiformes and some Columbiformes for the stratum, and Caprimulgiformes and some Columbiformes and Passeriformes for the low stratum.

\subsection{Seasonal Patterns for Frugivorous Bird Species}

A total of 29 frugivorous species were recorded during the sampling period (Table S2). Represented groups were Tinamiformes, Psittaciformes and Passeriformes. This last group included the majority of the frugivorous species, with Tyrannidae as the most represented family. Average number of species, sightings and diversity for frugivorous species in each sampling date are shown in Fig. 2. The temporal trend of species richness was similar to the pattern showed by all the species: the number of species rose in Spr1, peaked in higher stratum, Passeriformes for medium Sum1, declined markedly from Sum3 and remained in lower values during the rest of the sampling period (Fig. 2a). There were statistical significant differences when all sampling dates were compared together (Friedman test, $x^{2}=$ 45.56, $\mathrm{p}<.001$, $\mathrm{df}=11$ ). Some frugivorous species stayed only during summer, like Thectocercus acuticaudata (Veillot 1818), Griseotyrannus aurantioatrocristatus (D'Orbigny \& Lafresnaye 1837), Myiarchus swainsoni (Cabanis \& Heine 1859), Myiarchus tyrannulus (Statius Muller 1776), Myiodynastes maculatus (Statius Muller 1776), Phytotoma rutila (Veillot 1818), Serpophaga subcristata (Veillot 1817), Taraba major (Veillot 1816), Thamnophilus caerulescens (Veillot 1816), Thraupis bonariensis (Gmelin 1789) and Cyclarhis gujanensis (Gmelin 1789).
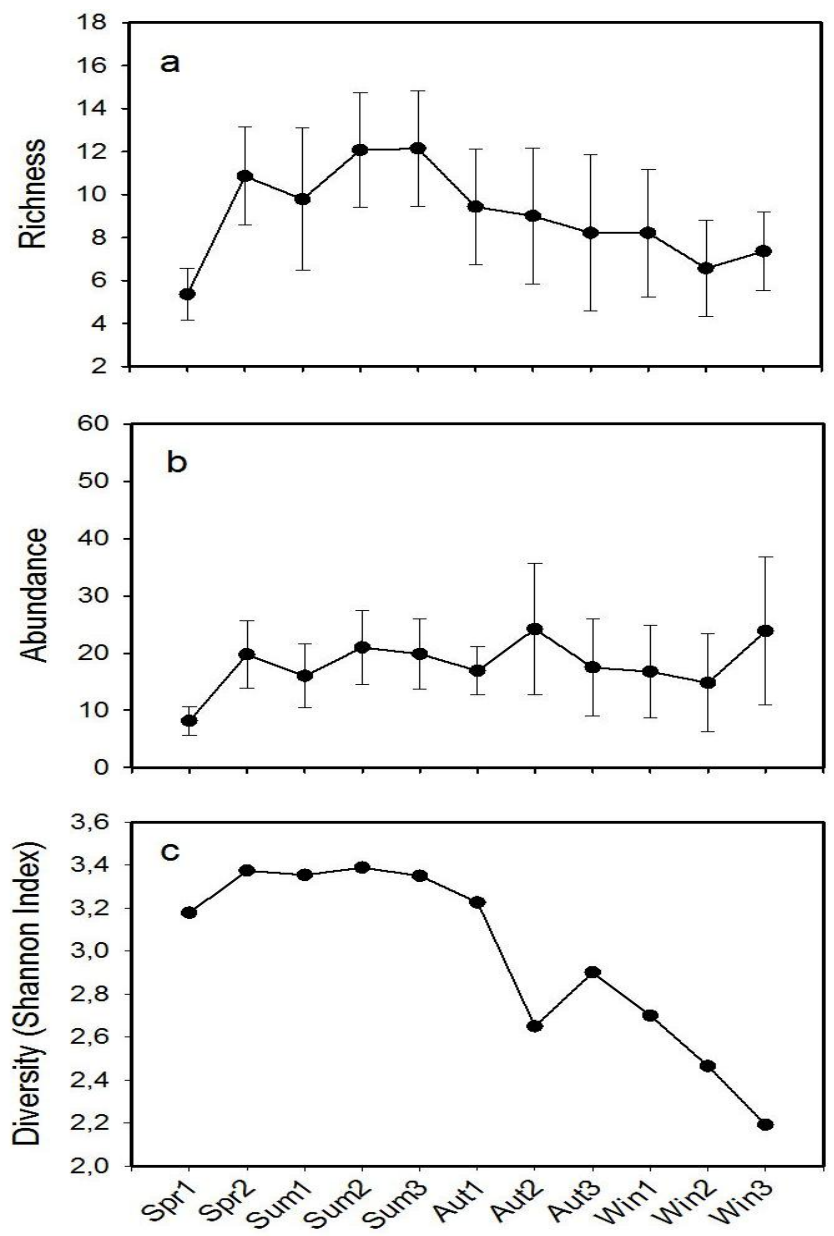

Fig. 1. a) Number of bird species (mean and sd), b) abundance as number of bird sightings (mean and sd) and c) Shannon Index (data from all transects in each sampling date pooled) for all species in each sampling date corresponding to spring (Spr), summer (Sum), autumn (Aut) and winter (Win) 

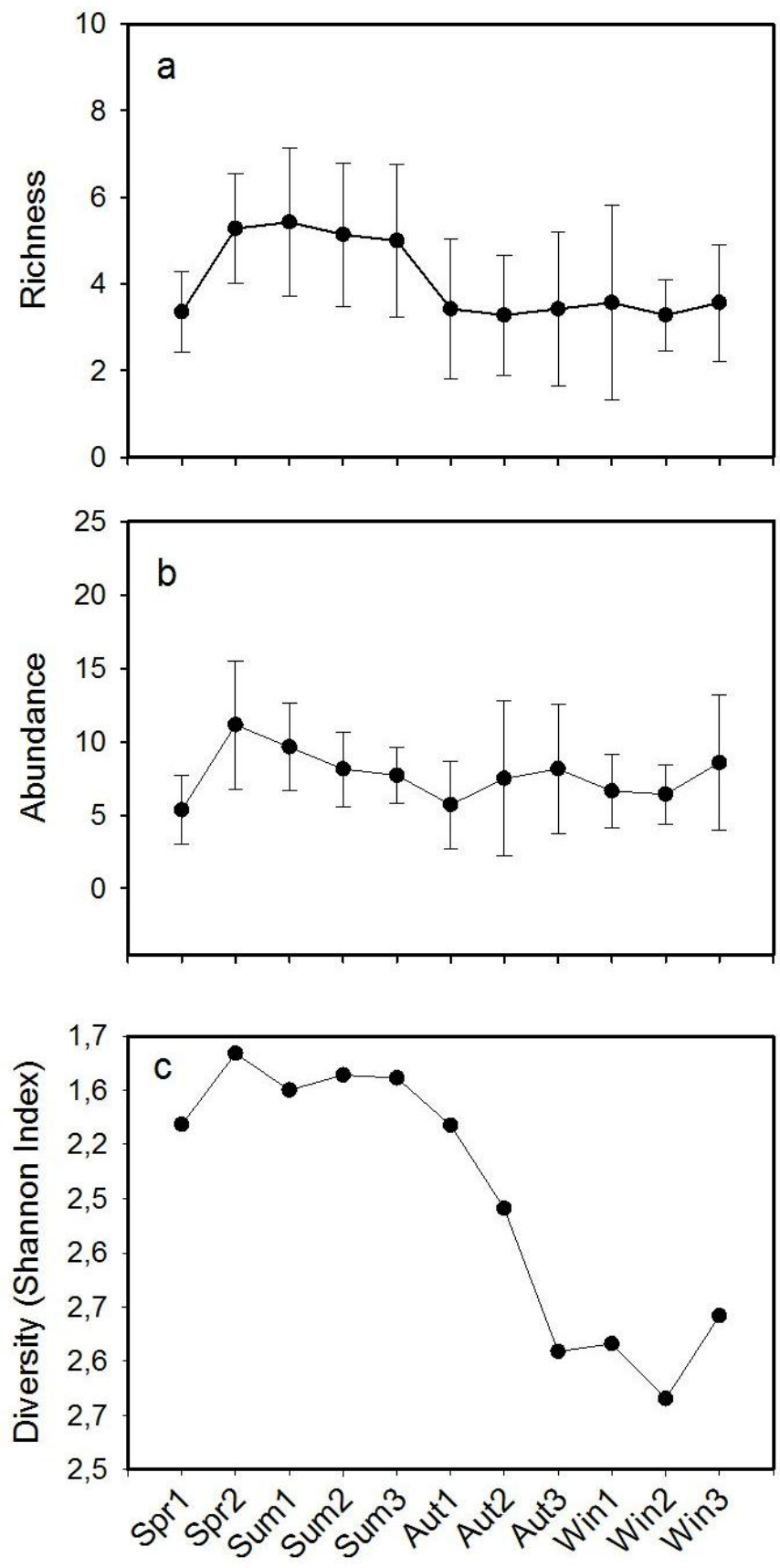

Fig. 2. a) Number of frugivorous bird species (mean and sd), b) abundance as number of frugivorous bird sightings (mean and sd) and c) Shannon Index for frugivorous species (data from all transects in each sampling date pooled) in each sampling date corresponding to spring (Spr), summer (Sum), autumn (Aut) and winter (Win)

Abundance showed almost a bimodal trend during the sampling period, with a small peak in Spr2 (Fig. 2b). This peak was mainly caused by an increase in the presence of Elaenia albiceps (D'Orbigny \& Lafresnaye 1837),

G. aurantioatrocristatus, Knipolegus striaticeps (D'Orbigny \& Lafresnaye 1837), and Suiriri suiriri
(Veillot 1818). When all dates were compared together, there were statistically significant differences in sightings (Friedman test, $x^{2}=$ 28.57, $p=.01$, df = 11). Diversity values showed by the Shannon Index showed the highest values during the first months of sampling, with a peak in Spr2 coincidentally with the peak in sightings. 
Then begun declining in the same date as richness, in Sum3. (Fig. 2c). Evenness ranged from 0.90 to 0.70 , whit the highest value corresponding to Aut2 and the lowest to Win1. The high evenness in Aut2 was consequence of the temporal disappearance of some species present until this date with very low sighting values, like $G$. aurantioatrocristatus, $M$. tyrannulus, M. maculates, S. subcristata, Turdus chiguanco (D'Orbigny \& Lafresnaye 1837), and Vireo olivaceous (Linnaeus 1766).

Results from the multivariate analysis CATPCA using species values and independent contrasts showed common overall results for the variables initiation and maximum of frugivorous species abundance, that were inversely or not correlated with duration of sightings, maximum abundance and total abundance along the sampling period (Figs. 3 and 4). The behaviour of these variables is mainly collected by CATPCA Dimension 1 , with $54.10 \%$ of explained variance $(0.83$ Cronbach's alpha) and $58.66 \%$ explained variance (0.86 Cronbach's alpha) for species values and independent contrasts respectively. However, the behaviour of the variable Diet changed when independent contrasts were used. From a closer relationship with sighting initiation and peak and a greater vector value (0.33) with species values data, Diet showed a more distant relationship with these sightings variables and a negligible vector value (0.07) when independent contrasts were used. At the same time the importance of Diet variable in Dimension 2 changed also, with a greater vector value when independent contrasts were used (0.61) compared with species values data (0.34), and this accounts for the larger vector showed by Diet in Fig. 4. However, the lower percentage of explained variance (17.80) and a very low Cronbach's alpha (0.078) for Dimension 2 when using independent contrasts compared with species value data $(24.88 \%$ and 0.39 respectively) is indicating that after removing phylogenetic effects differences in diet are not explaining seasonal patterns in forest frugivorous birds. CATPCA analysis also shows that the species relationships with variables are modified after discounting phylogenetic effects. Not only many species were differently related with the variables but also the dispersion of the species was greater in the biplot showing CATPCA results after applying independent contrasts (Fig. 4) compared with species values data (Fig. 3).

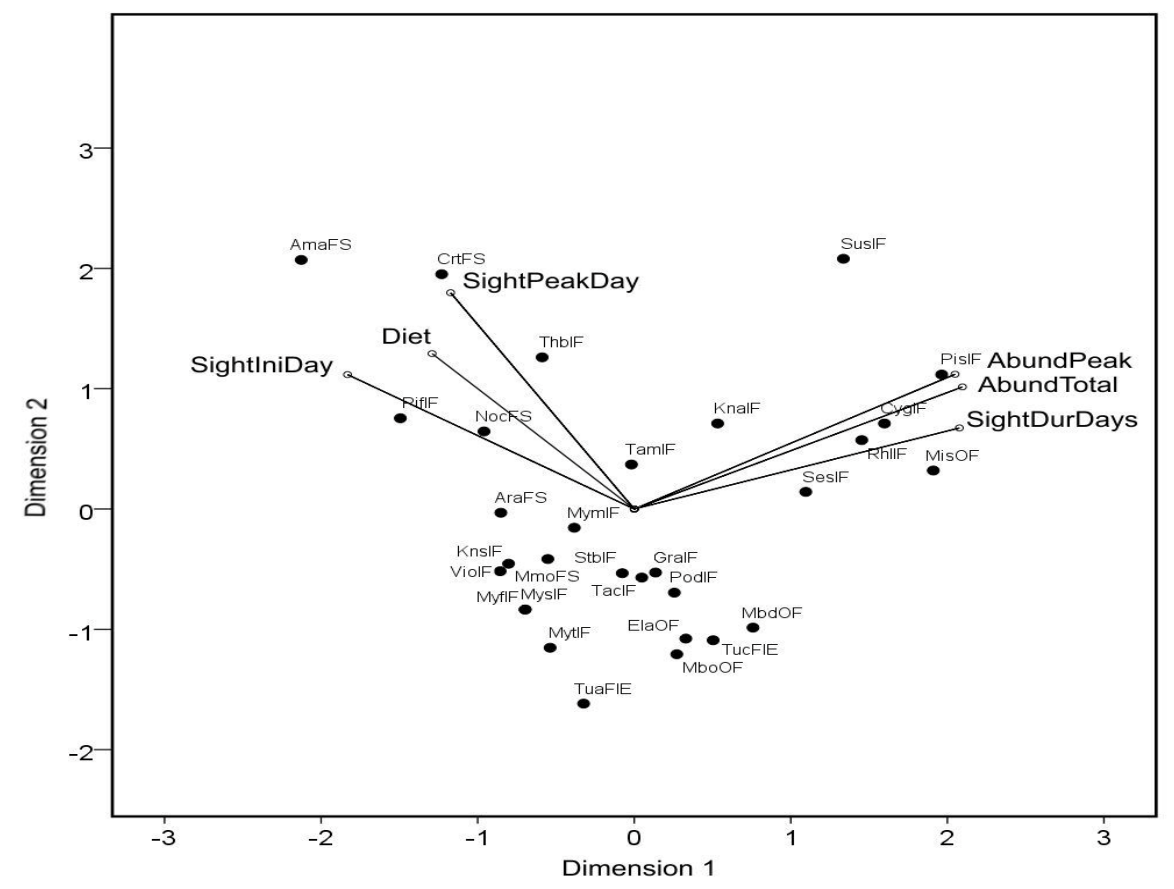

Fig. 3. CATPCA biplot (variables and species) of timing of appearance and abundance of frugivorous species and diet using species values. For each species, variables were Sightlni day: date of first sighting, sight peak day: date of maximun sightings, sight dur days: number of sighting days, abund peak: maximum number of sightings, abund total: total number of sightings through the sampling period. Dots represent species, labelled with abbreviated scientific names (three first letters) and diet (last capital letters. See text and Table S2. for species names and diet abbreviations 


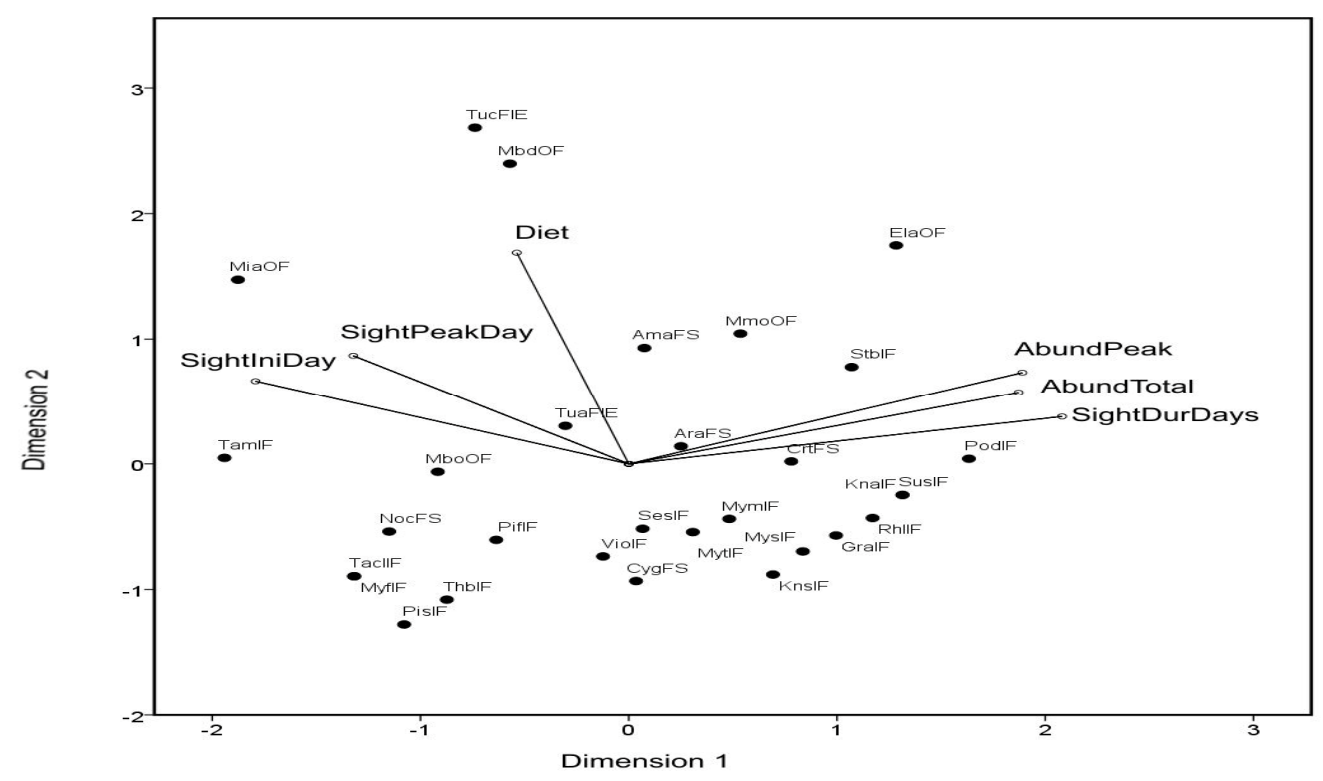

Fig. 4. CATPCA biplot (variables and species) of timing of appearance and abundance of frugivorous species and diet using species independent contrasts. Variables and species abbreviations as in Fig. 3

\subsection{Climatic and Habitat Variables, and Frugivorous Bird Seasonal Patterns}

Temporal variation of average photosynthetic photon flux density (PPFD), rainfall and fruit abundance during the study period is shown in Fig. 5. Both rainfall and PPDF showed an overall similar seasonal pattern, although PPFD began rising earlier during the dry season and peaked one month before (Sum1) (Fig. 5a) than rainfall peak (Sum2) (Fig. 5b). The onset of the heavy rain season occurred in Spr2. Rainfall and PPDF were temporally correlated $(r=0.70, P=.01)$. Fruits began appearing in spring, peaked during this season, and then decreased sharply to disappear during winter (Fig. 5c). Fruit abundance was highly correlated with PPFD (Spearman rho $=0.76, p<.001)$ but showed no significant correlation with rainfall (Spearman rho $=0.44, p=.17$ ).

Relationships between climatic (rainfall) and habitat variables (PPFD, fruit abundance) and frugivorous species richness (mean number of species), abundance (as mean number of sightings), and diversity (as Shannon Index) are shown in Fig. 6. Dimension 1, with $59.51 \%$ of explained variance (Cronbach's alpha 0.86), clearly separated spring, summer and autumn sampling dates from the last autumn date and winter dates, which did not show association with any variable. PPDF and fruit abundance were correlated with frugivorous richness (Spearman rho 0.67 and $0.65, p>.05)$ and diversity $(0.85$ and $0.87, p>0.01$ ), explaining most of the variance in both bird variables(vectors 0.95 and 0.82 respectively) but not in abundance. PPDF was not correlated and fruit abundance was negatively correlated with bird abundance (Spearman rho $-0.12, p=.73$ ). Rainfall did not explain the behaviour of any bird variable since it showed no significant correlations with any of them. Dimension 2, with $23.90 \%$ of explained variance (Cronbach's alpha 0.37 ), did not make a significant contribution.

\section{DISCUSSION}

In the semiarid Chaco forest studied bird assemblages of frugivorous species as well as the entire bird community showed some seasonal changes, mainly in species number and composition. Species richness increased during the summer months. However, the overall rate of bird abundance, taken as sightings, did not change. Species diversity, measured with the Shannon Index, varied following a trend similar to the species richness. This general pattern of seasonal variation is in agreement with seasonal bird assemblage variations reported by Codesido and Bilenca [2] in a semiarid forest located Northern in Argentina. More generally, seasonal changes in bird assemblage composition and species and guild abundance in bird communities have been reported by several authors [3-6, 48]. The seasonal changes showed by the totality of 
the species were also present when different trophic guilds were considered. Groups like insectivorous, carnivorous and nectarivorous birds also showed seasonal changes, with more species present and with greater abundances mainly during summer and autumn beginning. Granivorous birds, however, showed no seasonal variations in species richness or species abundance through the studied period, although a minor species turnover was present. This is in contrast with the seasonal changes reported by Capurro and Bucher [21,22] in a semiarid forest situated Northen-West in Argentina, who found an increase in granivorous abundance during the autumn and winter.
However, a similar trend to that found in this study was described by Codesido and Bilenca [2], who reported the lack of seasonal variations in this guild along the seasons. These authors attributed this behaviour to grain availability through the year due to the presence of crops near the studied forest. The same explanation may be suitable for the behaviour of the granivorous guild in the studied Chaco forest, since the area cultivated in the region with crops like corn and soybean has greatly increased since the 1990 decade [49]. The abundance of granivorous birds was also increased in the vicinity of farming locations in the Dry Chaco in Argentina [9].
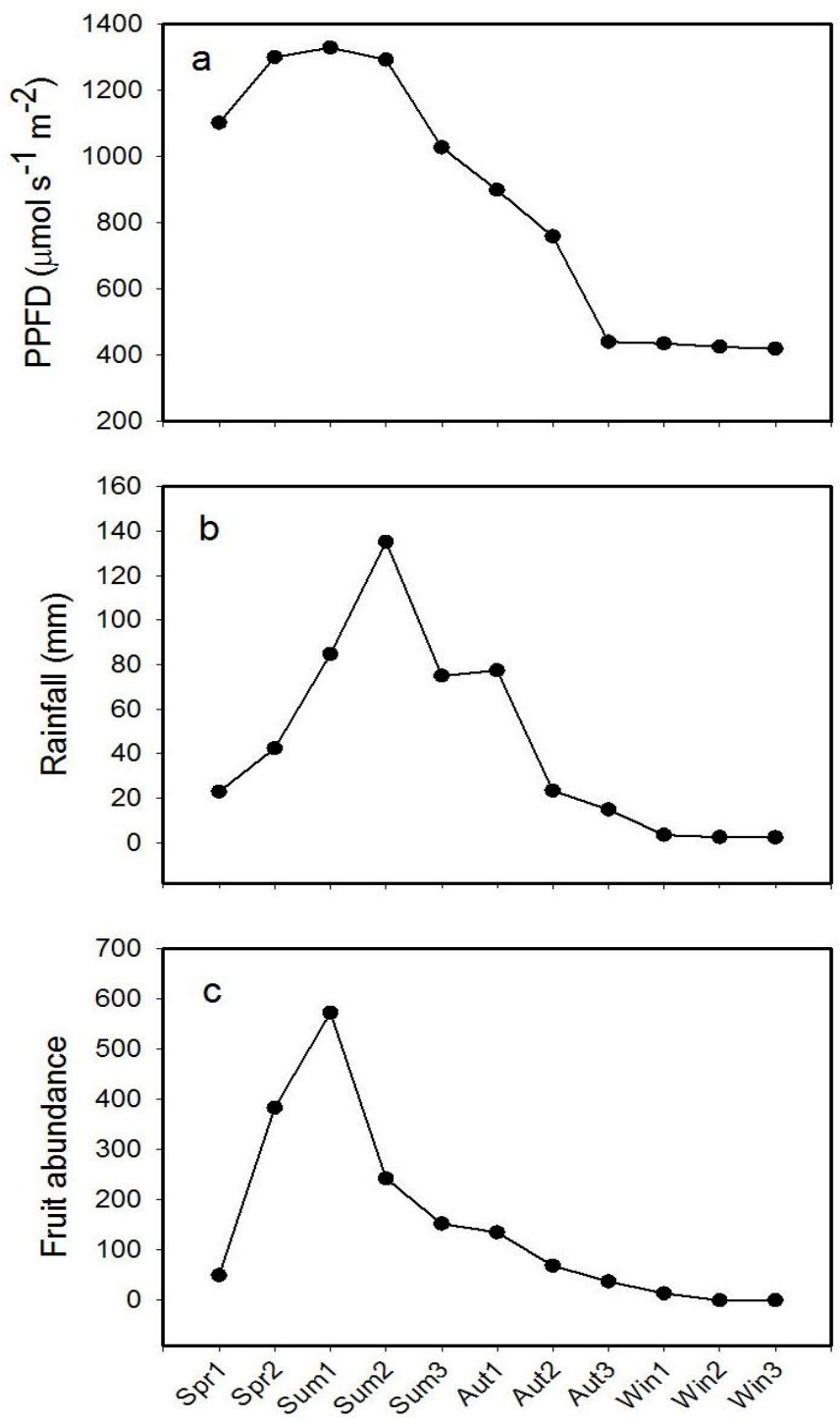

Fig. 5. a) Average photosynthetic photon flux density (PPFD), b) average monthly rainfall and c) total fruit abundance in each sampling date corresponding to spring (Spr), summer (Sum), autumn (Aut) and winter (Win) 


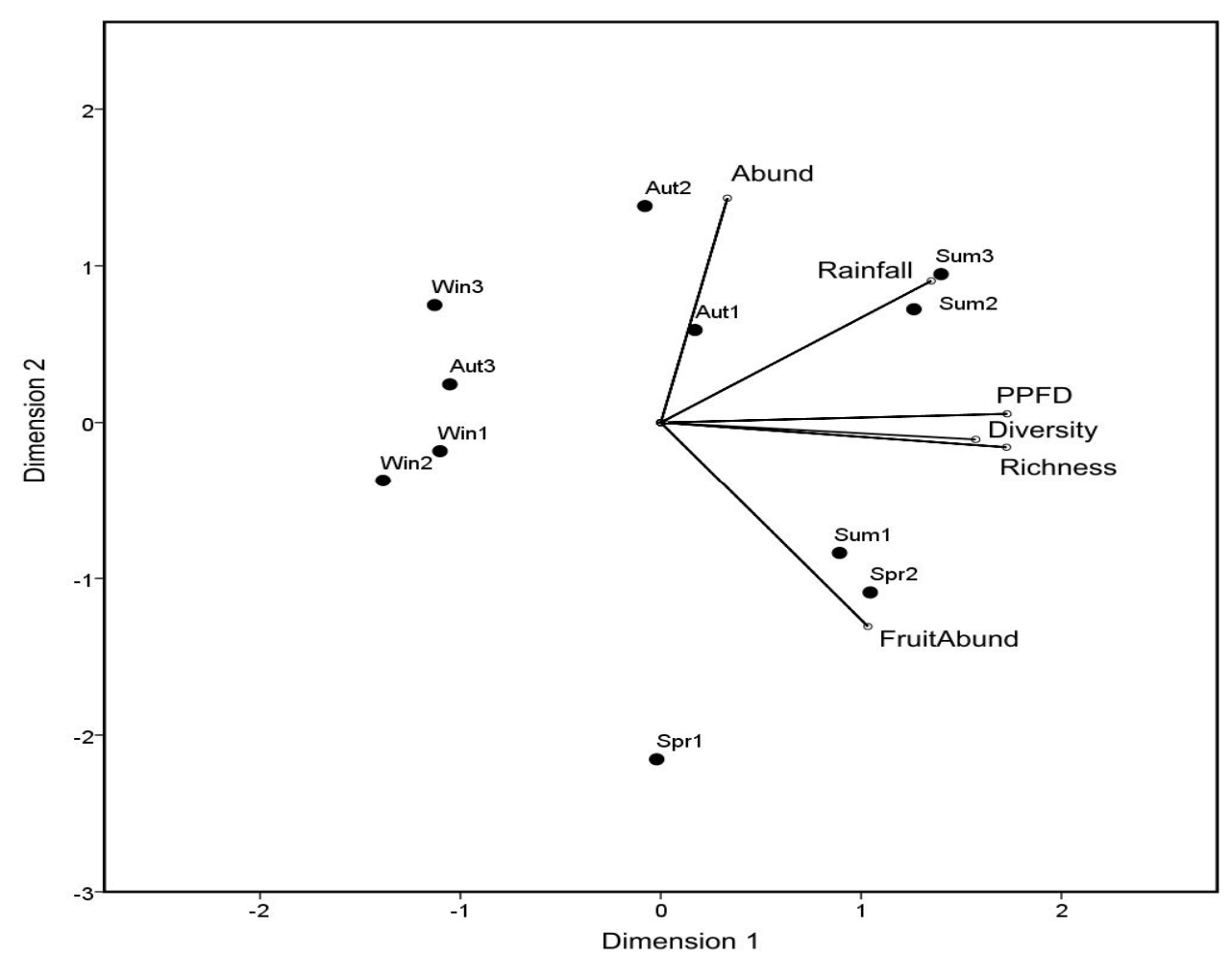

Fig. 6. CATPCA biplot (variables and sampling dates) of rainfall, PPFD, fruit abundance, richness, abundance and diversity of frugivorous species. Dots represent sampling dates corresponding to spring (Spr), summer (Sum), autumn (Aut) and winter (Win)

Considering in more detail the group focused in the work, the frugivorous guild, some of the species were only present in the forest during the summer months. In arid and semiarid subtropical habitats seasonal changes in bird assemblages have been attributed to seasonal variations in climatic habitat characteristics, like rainfall and temperature, which in turn promote changes in vegetation phenology and structure [1-6]. In this study, an association between seasonal changes in habitat and climatic variables (PPFD and rainfall) and frugivorous species richness and diversity was detected, but not with rainfall. Leaf flushing, flower and fruit phenological stages of fruting plants begin coincidentally with PPFD peak rather with rainfall peak [16]. Thus, the plant phenological pattern appears to explain the increase in bird richness in this forest in summer. In the case of frugivorous birds, as many of the species consume also insects besides fruits, plant phenological stages previous to fruiting may represent the beginning of resource availability. Insect activity is highly associated to climatic variables in semiarid Chaco habitats [50]. This also may explain the homogenous utilisation of vegetation strata by frugivorous birds, probably related with the facultative switch between insect and fruit consumption habits showed by many frugivorous bird species.

In contrast with species richness and diversity, frugivorous species abundance was not correlated to habitat variables. This seems to be counterintuitive, since an increase in frugivorous bird abundance per species during the fruit season was expected, as found by several previous works $[2,4,6,14,15,51]$. However, some frugivorous species (E. albiceps, $G$. aurantioatrocristatus, $K$. striaticeps, $M$. maculatus, $S$. suiriri) showed a peak in abundance during spring, coincidentally with the peak in fruit abundance. The even abundance distribution of many frugivorous species through the year again may be due to their diet, in many cases composed not only by fruits but also by insects or seeds, in different proportions. Thus, for example, Rhinocrypta lanceolata (Geoffroy Saint-Hilaire 1832) and Stigmatura budytoides (D'Orbigny \& Lafresnaye 1837), that eats fruits but also insects, maintain an even abundance through the year, with a small decrease during the winter months. In the Chaco forest there are some other plant species producing fruits potentially useful for birds, like Opuntia spp., Capparis atamisquea, Geoffroea decorticans and 
Prosopis spp., all of them mainly consumed by Psittacidae species, although they are not present in the studied forest or have very low abundances [20]. However, we may consider these other plant species as a potentially, although minor, available source of fruits for birds present in the study area and moving locally.

When controlling for phylogenetic effects on the frugivorous guild, the overall results held. However, after removing phylogenetic effects differences in diet were not longer explaining seasonal patterns of appearance of forest frugivorous birds. Also, most of species were differently related with the climatic and habitat variables considered and the dispersion of the species in the ordination space was greater after discounting the phylogenetic effects. Although previous studies addressing the issue of phylogenetic effects on activity of assemblages of frugivorous birds are scarce, Carnicer et al. [52] reported significant effects of phylogeny in the temporal activity of the frugivorous guild in Spain. Adaptive evolutionary processes acting on beak morphology and other traits would ultimately determine the ability of bird species to switch to fruits and the relative percentage of fruits in the diet for each species $[11,12,53]$. In another work analysing the relationship between frugivorous bird abundances and resource availability in a tropical rain forest, phylogenetic effects were also present [54]. The findings of this work differ from those from Cofré et al. [55], who found that local bird abundances exhibited low or no significant phylogenetic signal. However, in a recent work, Barganaud et al. [56] found that on large spatial scales bird occurrence patterns were largely determined by bird species traits, while the phylogenetical signal was stronger when habitat or migratory behaviour was considered and weaker when the food guilds was considered instead.

Finally, it is important to consider that factors other than temporal patterns of food availability may also seasonally affect species densities, for example, breeding. This, however, might not be entirely independent of food resource availability, as the high rate of resource provisioning needed during breeding requires reliable and abundant food resources [57].

\section{CONCLUSION}

We conclude that habitat characteristics, mainly PPFD and fruit abundance, are shaping the seasonal species composition (richness and diversity), although not abundance, of frugivorous bird assemblages in semiarid Chaco forests. The importance of the frugivorous diet diversification, as a species' trait factor that could be contributing to shape the seasonal arrangement of frugivorous birds, was secondary and mainly related to the timing of appearance in the favourable season. However, even this modest contribution of diet diminished when the phylogeny were taken into account, showing a strong phylogenetic signal.

\section{ACKNOWLEDGEMENTS}

We thank Mike Dodd, for introducing us on PIC analysis and for helpful comments on earlier stages of the work and the manuscript. Juan Fornoni, Ana Calviño and Norma Cech helped during field work. This work was supported by the Secretaría de Ciencia y Técnica de la Universidad Nacional de Córdoba (SECyT), Consejo de Investigaciones Científicas y Tecnológicas de la Provincia de Córdoba (CONICOR), and Consejo Nacional de Investigaciones Científicas y Técnicas (CONICET), República Argentina. DEM is member of CONICET. The study was undertaken following the current normative for research in protected areas in Córdoba Province (Argentina).

\section{COMPETING INTERESTS}

Authors have declared that no competing interests exist.

\section{REFERENCES}

1. Wiens JA. The ecology of bird communities. Foundations and patterns. Cambridge: Cambridge Univ. Press; 1989;1.

2. Codesido M, Bilenca D. Variacion estacional de un ensamble de aves en un bosque subtropical semiarido del Chaco, Argentina. Biotropica. Spanish. 2004;36:544-554.

3. Herrera CM. Seasonal variation in the quality of fruits and diffuse coevolution between plants and avian dispersers. Ecology. 1982;63:773-785.

4. Loiselle B, Blake J. Temporal variations in birds and fruits along an elevational gradient in Costa Rica. Ecology. 1991;72:180-193.

5. Marone L. Seasonal and year to year fluctuations of bird populations and guilds 
in the Monte Desert, Argentina. J Field Ornithol. 1992;63:296-308.

6. Cueto VR, Lopez de Casenave J. Seasonal changes in bird assemblages of coastal woodlands in east central Argentina. Stud Neotrop Fauna \& Environ. 2000;35:173-177.

7. Diamond SE, Frame AM, Martin RA, Buckley LB. Species' traits predict phenological responses to climate change in butterflies. Ecology. 2011;92:1005-1012.

8. Zurita GA, Zuleta GA. Bird use of logging gaps in a subtropical mountain forest: The influence of habitat structure and resource abundance in the Yungas of Argentina. Forest Ecol Manag. 2009;257:271-279.

9. Macchi L, Grau HR. Piospheres in the dry Chaco. Contrasting effects of livestock puestos on forest vegetation and bird communities. J Arid Environ. 2012;87:176187.

10. Harvey PH, Read AF, Nee S. Why ecologists need to be phyllogenetically challenged. J Ecol. 1995;83:535-536.

11. Jordano Frugivory $P$. external morphology and digestive system in Mediterranean sylviid warblers Sylvia spp. Ibis 1987;129:175-189.

12. Abzhanov A, Protas M, Grant BR, Grant PR, Tabin CJ. Bmp4 and morphological variation of beaks in Darwin's finches. Science. 2004;305:1462-1464.

13. Rubolini D, Møller AP, Rainio $\mathrm{K}$, Lehikoinen E. Intraspecific consistency and geographic variability in temporal trends of spring migration phenology among European bird species. Climate Res. 2007;35:135-146.

14. Loiselle B, Blake J. Annual variations in birds and plants of a tropical second growth woodland. Condor 1994;96:368380.

15. Malizia LR. Seasonal fluctuations of birds, fruits and flowers in a subtropical forest of Argentina. Condor 2001;103:45-61.

16. Marco DE, Páez S. Phenology and phylogeny of animal-dispersed plants in a Dry Chaco forest (Argentina). J Arid Environ. 2002;52:1-16.

17. Ramella L, Spichiger R. Interpretación preliminar del medio físico y de la vegetación del Chaco Boreal. Contribución al estudio de la flora y de la vegetación del Chaco. I. Candollea. 1989;44:640-680.
18. Luti R, Solis M, Galera F, Muller N, Berzal M, Nores M, et al. editors. Geografía Física de la Provincia de Córdoba, Buenos Aires: Boldt. Spanish; 1979.

19. Páez S, Marco D. Seedling habitat structure in dry Chaco forest (Argentina). J Arid Environ. 2000;46:57-68.

20. Páez S. Regeneración de árboles y arbustos en un bosque semiárido del Chaco Occidental. PhD dissertation. Universidad Nacional de Córdoba, Argentina. Spanish; 2000.

21. Capurro HA, Bucher EH. Poblaciones de aves semilleros y disponibilidad de semillas en el bosque chaqueño de Chamical. Ecosur. 1982;9:117-131

22. Capurro HA, Bucher EH. Variacion estacional en la comunidad de aves del bosque chaqueño de Chamical. Physis Secc. 1986;C-44:1-6.

23. Davis E. Seasonal status, relative abundance, and behavior of the birds of Concepcion, Departamento Santa Cruz, Bolivia. Fieldiana Zoology N.S. 1993;71.

24. Kratter AW, Sillet TS, Chesser RT, O'Neill JP, Parker A, Castillo A. Avifauna of a Chaco locality in Bolivia. Wilson Bull. 1993;105:114-141.

25. Lopez de Casenave J, Pelottos JP, Caziani SM, Mermozy M, Protomastro J. Responses of avian assemblages to a natural edge in a Chaco semiarid forest in Argentina. Auk. 1998;115: 425-435.

26. Legname PR. Arboles indígenas del Noroeste argentino. Opera Lilloana Fundación Miguel Lillo, Tucumán, Argentina. Spanish. 1982;34.

27. Aizen $M$, Feinsinger $P$. Forest fragmentation, pollination, and plant reproduction in a Chaco dry forest, Argentina. Ecology. 1994;75:330-351.

28. Myers DR. Solar radiation modeling and measurements for renewable energy applications: Data and model quality. Energy. 2005;30:1517-1531.

29. Felsestein J. Phylogenies and the comparative method. Am Nat. 1985;125:115.

30. Harvey $\mathrm{PH}$, Pagel MD. The comparative method in evolutionary biology. Oxford: Oxford University Press; 1991.

31. Harvey $\mathrm{PH}$, Purvis A. Comparative methods for explaining adaptations. Nature 1991;351:619-624. 
32. Purvis A, Rambaud A. Comparative analysis by independent contrasts (CAIC): an Apple Macintosh application for analysing comparative data. Computer Appl Biosc. 1995;11:247-251.

33. Harvey $\mathrm{PH}$. On rethinking allometry. J Theor Biol. 1982;95:37-41.

34. Livezey BC, Zusi RL. Higher-order phylogeny of modern birds (Theropoda, Aves: Neornithes) based on comparative anatomy. II. Analysis and discussion. Zoo J Linn Soc-Lond. 2007;149:1-95.

35. Treplin $S$, Siegert $R$, Bleidorn $C$, Thompson HS, Fotso R, Tiedemann R. Molecular phylogeny of songbirds (Aves: Passeriformes) and the relative utility of common nuclear marker loci. Cladistics. 2008;24:328-349.

36. Ohlson AN, Fjeldsa J, Ericson GP. Tyrant flycatchers coming out in the open: phylogeny and ecological radiation of Tyrannidae (Aves, Passeriformes). Zool Scr. 2008;37:315-335.

37. Wright TF, Schirtzinger EE, Matsumoto T, Eberhard JR, Graves GR, Sanchez JJ, et al. A multilocus molecular phylogeny of the parrots (Psittaciformes): support for a Gondwanan origin during the Cretaceous. Mol Biol Evol. 2008;25:2141-2156.

38. Tavares ES, Baker AJ, Pereira SL, Miyaki CY. Phylogenetic relationships and historical biogeography of Neotropical parrots (Psittaciformes: Psittacidae: Arini) inferred from mitochondrial and nuclear DNA Sequences. Syst Biol. 2006;55:54470.

39. Russello MA, Amato GA. molecular phylogeny of Amazona: implications for Neotropical parrot biogeography, taxonomy, and conservation. Molecular Phylogenetics and Evolution. 2004;30: 421-437.

40. Cicero C, Johnson NK. Molecular phylogeny and ecological diversification in a clade of New World songbirds (genus Vireo). Molecular Ecology. 1998;7:13591370.

41. Voelker G, Rohwer S, Bowie RCK, Outlaw DC. Molecular systematics of a speciose, cosmopolitan songbird genus: Defining the limits of, and relationships among, the Turdus thrushes. Mol Phylogenet Evol. 2007;42:422-434.

42. Barker FK. Monophyly and relationships of wrens (Aves: Troglodytidae): a congruence analysis of heterogeneous mitochondrial and nuclear DNA sequence data. 2004;31(2):486-504.

43. Irestedt $\mathrm{M}$, Fjeldsa J, Ericson GP. Phylogenetic relationships of woodcreepers (Aves: Dendrocolaptinae)incongruence between molecular and morphological data. J Avian Biol. 2004;35: 280-288.

44. Lanyon SM, Omland KE. A molecular phylogeny of the blackbirds (Icteridae): five lineages revealed by cytochrome-b sequence data. The Auk; 1999;116:629639.

45. Klicka J, Burns K, Spellman GM. Defining a monophyletic Cardinalini: A molecular perspectiva. Mol Phylogenet Evol. 2007;45:1014-1032.

46. Ericson PGP, Zuccon D, Ohlson Jl, Johansson US, Alvarenga $\mathrm{H}$, Prum RO. Higher-level phylogeny and morphological evolution of tyrant flyycatchers, cotingas, manakins, and their allies (Aves: Tyrannida). Mol Phylogenet Evol. 2006;40:471-483.

47. Birdsley JS. Phylogeny of the tyrant flycatchers (tyrannidae) based on morphology and behaviour. Auk; 2002;119:715-734.

48. Avery $M$, van Ripper C III. Seasonal changes in bird communities of the Chaparral and blue oak-woodlands in central California. Condor. 1989;91:288295.

49. Pengue WA. Produccion agroexportadora e (in) seguridad alimentaria: El caso de la soja en Argentina. Rev Iber Econ Ecol. Spanish. 2004;1:46-55.

50. Marco DE, Calviño AA, Páez S. Patterns of flowering and fruiting in populations of Larrea divaricata in dry Chaco (Argentina). J Arid Environ. 2000;44:327-346.

51. Levey DI. Spatial and temporal variations in Costa Rican fruits and fruit-eating bird abundance. Ecol Monogr. 1988;58:251265.

52. Carnicer J, Jordano $P$, Melián CJ. The temporal dynamics of resource use by frugivorous birds: a network approach. Ecology. 2009;90:1958-1970.

53. Wu P, Ting-Xin J, Suksaweang S, Widelitz $\mathrm{RB}$, Chuong C. Molecular shaping of the beak. Science. 2004;305:1465-1466. 
54. Walker JS. Resource use and rarity among frugivorous birds in a tropical rain forest on Sulawesi. Biol Cons. 2006;1:60-69.

55. Cofré Hernán L, Böhning-Gaese K, Marquet PA. Rarity in Chilean forest birds: which ecological and life-history traits matter? Divers Distrib. 2007;13:203-212.

56. Barnagaud JY, Kissling DW, Sandel B, Eiserhardt WL, Şekercioğlu ÇH, Enquist
BJ, Tsirogiannis C, Svenning JC. Ecological traits influence the phylogenetic structure of bird species co-occurrences worldwide. Ecol Lett. 2014;17:811-820.

57. Blackburn TM, Lawton JH, Gregory RD. Relationships between abundances and life histories of British birds. J Anim Ecol. 1996;65:52-62.

(C) 2015 Marco et al.; This is an Open Access article distributed under the terms of the Creative Commons Attribution License (http://creativecommons.org/licenses/by/4.0), which permits unrestricted use, distribution, and reproduction in any medium, provided the original work is properly cited.

Peer-review history:

The peer review history for this paper can be accessed here:

http://www. sciencedomain.org/review-history. php?iid=747\&id=22\&aid=7186 